\title{
Corrigendum
}

\section{Corrigendum to “On Two-Level State-Dependent Routing Polling Systems with Mixed Service"}

\author{
Guan Zheng, ${ }^{1}$ Yang Zhijun, ${ }^{2}$ Qian Wenhua, ${ }^{1}$ and He Min ${ }^{1}$ \\ ${ }^{1}$ School of Information Science and Technology, Yunnan University, Kunming 650091, China \\ ${ }^{2}$ Educational and Scientific Institute, Educational Department of Yunnan Province, Kunming 650223, China \\ Correspondence should be addressed to Guan Zheng; gz_627@sina.com \\ Received 23 May 2016; Accepted 8 June 2016
}

Copyright (c) 2016 Guan Zheng et al. This is an open access article distributed under the Creative Commons Attribution License, which permits unrestricted use, distribution, and reproduction in any medium, provided the original work is properly cited.

In the article titled "On Two-Level State-Dependent Routing Polling Systems with Mixed Service" [1], there was an error in the "Acknowledgments" section, which should be corrected as follows:

This work was supported by a Grant from the National Science Foundation of China (nos. 61463051 and 61461054), the National Science Foundation of Yunnan Province (no. 2012FD002), and the Science Foundation of Yunnan Provincial Department (no. 2014Z010).

\section{References}

[1] Z. Guan, Z. Yang, W. Qian, and M. He, "On two-level statedependent routing polling systems with mixed service," Mathematical Problems in Engineering, vol. 2015, Article ID 109325, 9 pages, 2015. 


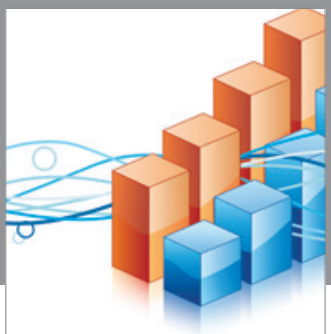

Advances in

Operations Research

vatem alat4

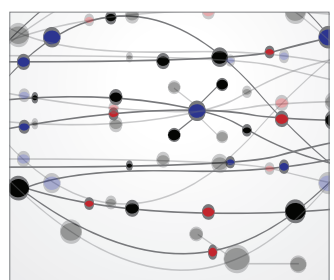

\section{The Scientific} World Journal
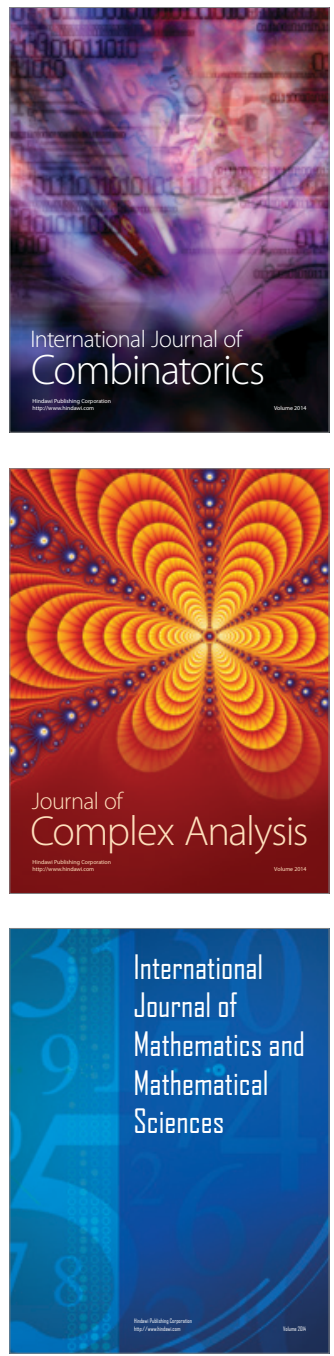
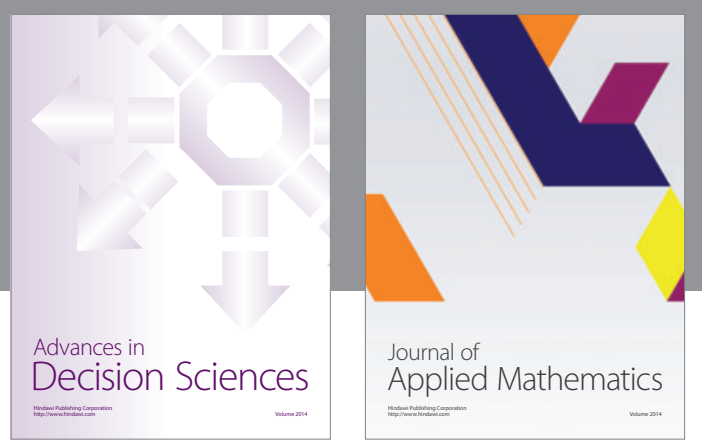

Algebra

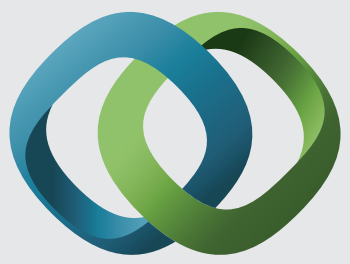

\section{Hindawi}

Submit your manuscripts at

http://www.hindawi.com
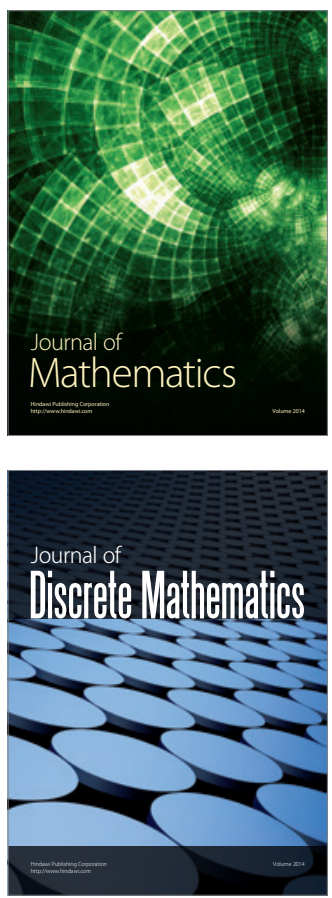

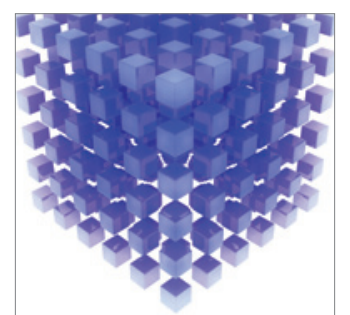

Mathematical Problems in Engineering
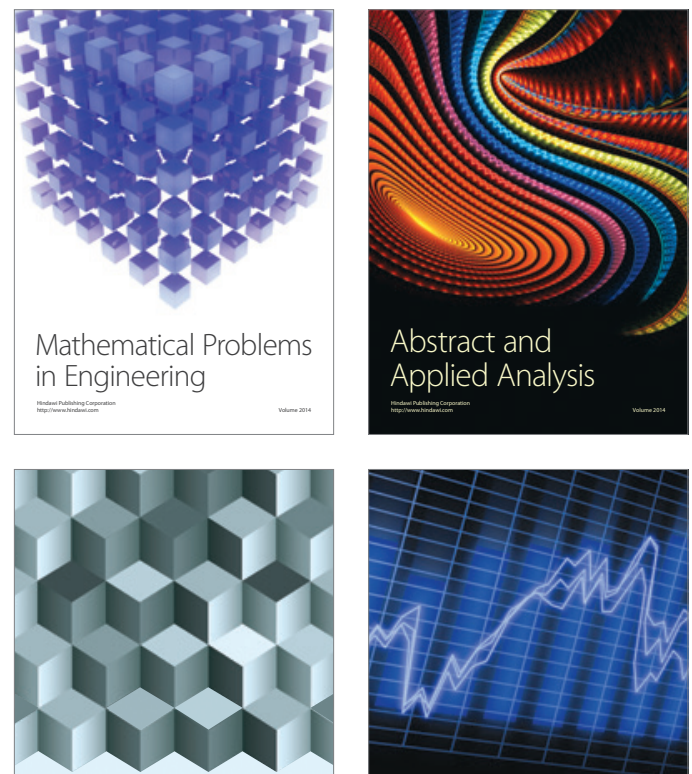

Journal of

Function Spaces

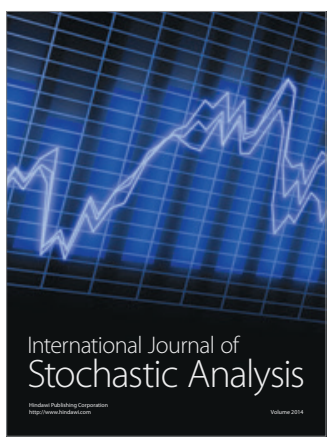

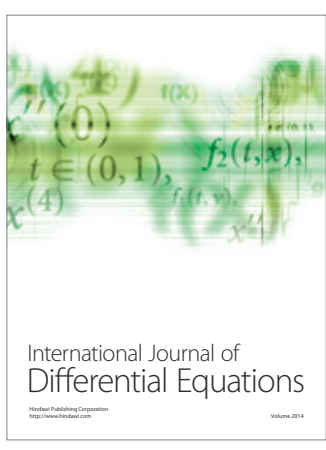
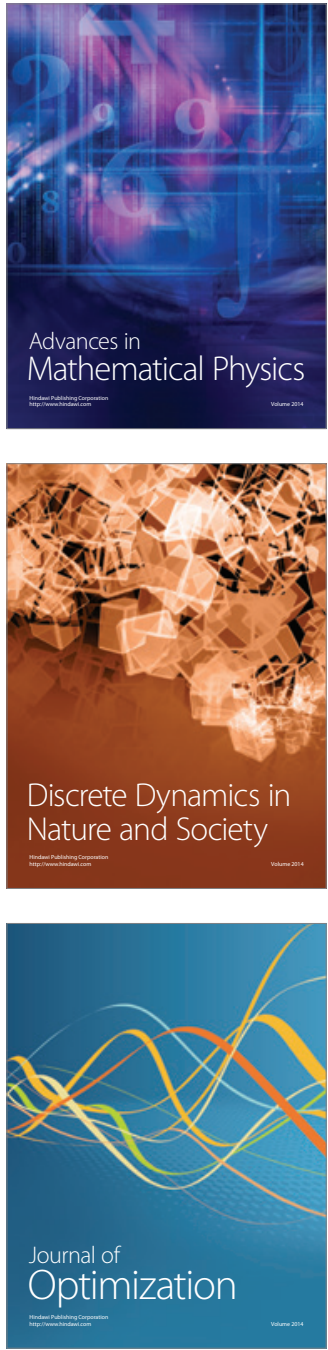